\title{
Professor Alfred Felix Landon Beeston 1911-1995
}

Some twenty years ago a documentary on the University of Oxford was shown on television. Inevitably the question of the Oxford eccentric came up and on screen there appeared, without comment, a brief shot of the steps of the Sheldonian Theatre where a portly figure in full academic dress, straggly grey hair hanging down to his shoulders, and a Woodbine dangling from his lips stared vacantly into the middle distance, giving the impression of one immersed in profound thought on some intractable problem. And that is almost certainly what Freddie Beeston, Laudian Professor of Arabic at the University of Oxford, was doing at that moment. For indeed it was he, in a pose so familiar to and beloved of his many colleagues and friends. We will never know what the problem at that moment was--perhaps the elucidation of an obscure taqdir in a verse of pre-Islamic poetry or thoughts on the chronological implications of the Himyarite Era in the South Arabian inscriptions-but Beeston was a man who rarely gave his acute mind a rest from the multitude of problems which should properly exercise the thoughts of the professional scholar. No one could deny him a place among the giants of British Orientalism, but if the Wrights, the Arberrys, the Nicholsons are perhaps more memorable, it can only be because they were given to producing major text editions and field studies which now form the basis of modern research into classical Arabic and Islamic culture. Beeston was more concerned with the building blocks of the language, the technical means whereby precise nuances can be conveyed to the reader to enable him to gain a deeper understanding of his material rather than be swayed by his professional expectations of a particular text. Beeston's publications tended to be of modest bulk, usually in the form of articles, where his pioneering insights and concise observations would be set out lucidly, courteously, and persuasively.

Born in London on 23 February 1911, Beeston received a thorough classical grounding at Westminster School which undoubtedly provided the stimulus for the precise and exacting analytical method he employed throughout his career. He discovered his bent for language investigation when he was yet a boy and was able to develop it with the active encouragement and, when appropriate, financial assistance of his father, a draughtsman in a firm of patent agents, and the sympathetic nurturing of his beloved mother. After some experimenting with various European languages, including Welsh, which remained a favourite with him, he developed a peculiar fascination for and rapport with Arabic and Chinese (Ancient Egyptian was 'too archeological') and for some time was uncertain which of these would occupy his future attention. It was pure chance that gave the advantage to Arabic. He had found the Chinese phrase books which came his way less than satisfactory for his analysis of that language, but happened to acquire in a second-hand book shop a copy of Palmer's Arabic grammar of 1874, still useful despite its age. The scholarly and comprehensive treatment of this work proved more congenial to him and provided him with the basis upon which to embark on the course of private study which would lead to his position of academic pre-eminence when he reached the apex of his career.

At the age of 14, he stumbled by chance upon the small collection of South Arabian inscribed stones housed rather haphazardly within the Egyptian Collection of the British Museum and seemed to appreciate instinctively that

(c) School of Oriental and African Studies, University of London 1997 


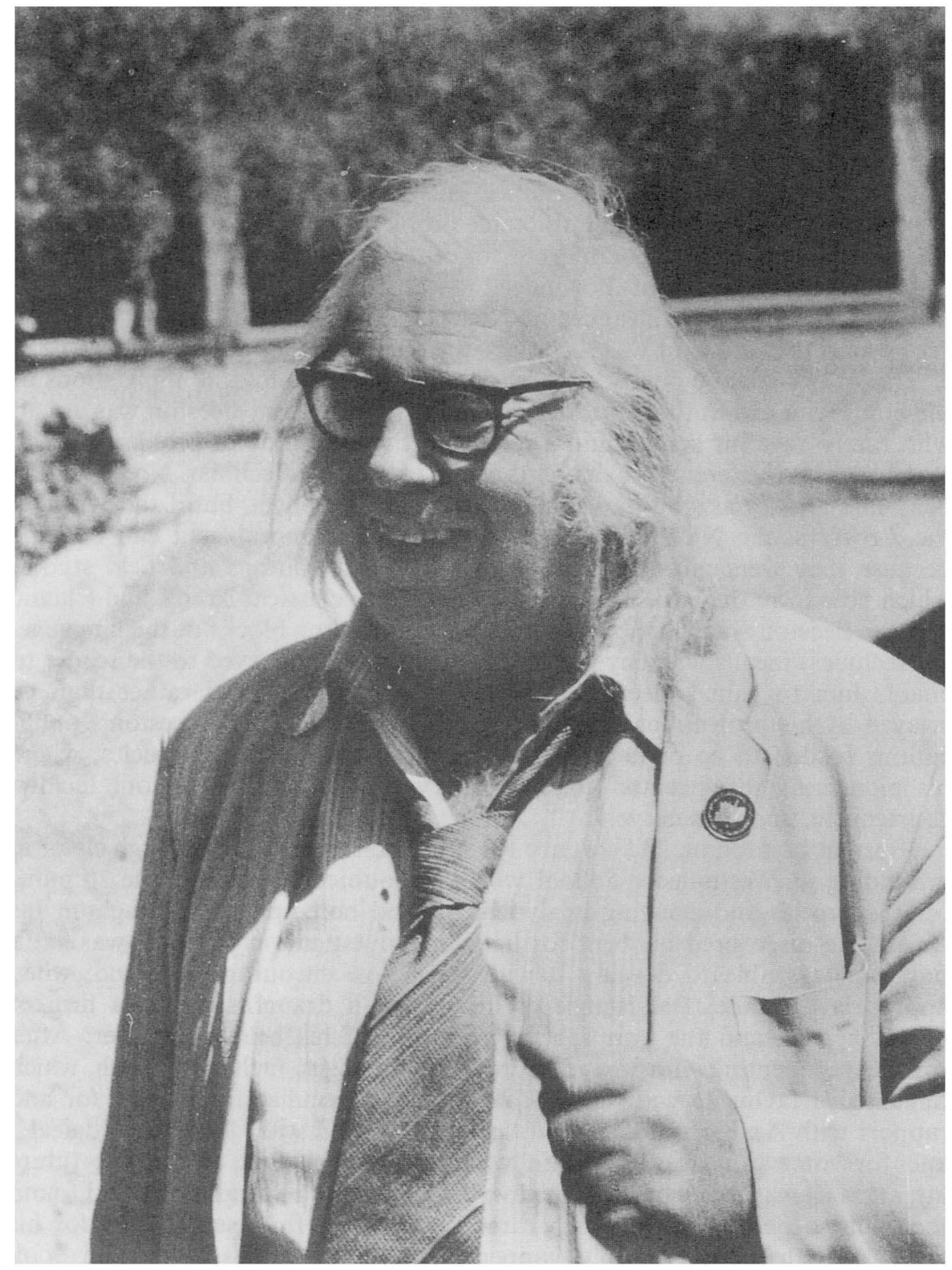

Professor A. F. L. Beeston in Yemen. Reproduced from Sayhadica: recherches sur les inscriptions de l'Arabie préislamique offertes par les collègues au Profésseur A. F. L. Beeston, (ed.) Ch. Robert and M. Bāfxaqīh (Paris: Paul Geuthner, 1987). 
here he had discovered something to which he could make a particular personal commitment. Inspired by the geometrical austerity of the letter forms, which very much appealed to him, and probably by the distinctly Semitic characteristics of the as yet imperfectly understood language, he set about familiarizing himself with it - a formidable prospect for one so young since the only grammar available would have been a Latin description by the eminent Italian Semitist Ignazio Guidi (1924), and the Chrestomathia of Carlo Conti Rossini (1931) had not yet appeared. Old South Arabian maintained its peculiar fascination with him for the rest of his long academic career and proved the field in which he would make his most substantial and influential contribution.

In 1929 he proceeded to Christ Church College, Oxford, to read for the usual Classical Tripos but, realizing that Semitic languages offered more scope to his enquiring mind, switched to Arabic and Persian (with an Old South Arabian option). On his own admission he concentrated more on Arabic than on Persian, though his subsequent career at the Bodleian suggests that he may have applied himself to Persian more than he admits. After graduation with First Class Honours in 1933, he registered to study for the D.Phil. degree under Professor D. S. Margoliouth (1858-1940) in the field of Old South Arabian. Margoliouth, whose teaching approach proved congenial to Beeston, was another of the giants of Arabic scholarship of the time and perhaps the only authority in this country who had himself made a contribution, albeit modest, to the elucidation of the South Arabian monuments. Under his supervision Beeston was able to produce a thesis, published privately as Sabaean inscriptions (Oxford, 1937) and still of value, in which he selected a number of inscriptions in the language, established their readings, and provided them with translations and a scholarly commentary which revealed a methodological and critical approach on the author's part far in advance of most of the continental specialists of his time. It seems that Beeston already had sensed the independence of South Arabian language and culture from the rest of the Peninsula, and the need to interpret its documents by internal analysis. Shortly afterwards two articles appeared under his name, respectively in the $J R A S$ and in Le Muséon-the latter a journal to which he was later to contribute a long series of seminal articles, many of them specific investigations of vocabulary fields, which were to establish his position as the leading authority in the field. Finally in 1939 appeared his "Appendix" to H. St. J. B. Philby's Sheba's daughters, where he translated and commented on the texts collected by the author during his journey from the Empty Quarter, which he had just 'crossed', past the desert of Ramlat Sab'atayn towards northern Yemen.

By the mid-30s Beeston realized that he must choose a career reflecting his interests and decided that librarianship, with its potential within orientalism, best fitted the bill. By good fortune he was able in 1935 to obtain the post of sub-librarian at the Bodleian Library - preferred by him to the British Museum, the other possibility at that time, since he recognized the advantages offered by Oxford through its libraries and its more congenial pace of life, in pursuing his own particular scholarly interests. His career was to be interrupted in 1940 when he embarked on six years of military service, latterly as captain, in the Intelligence Corps, firstly in Egypt and then in Palestine, where he lost no opportunity to develop and improve on his knowledge of the Arabic colloquials and could on more than one occasion impress the locals with his fine knowledge of the classical idiom. Released from his war service in 1946 he returned to Oxford where the retiral of the Keeper of Oriental Books and Manuscripts offered him the opportunity to apply, successfully, for that post, which he 
occupied till 1955. He adapted to it enthusiastically and with considerable success, priding himself on having been able to acquire a number of important manuscripts for the collection at reasonable prices. His work with the Bodleian culminated in the publication by OUP in 1955 of his Catalogue of ... the Additional Persian manuscripts [in the Bodleian Library]. His innate loyalty to Arabic had not, it seems, blinded him to the needs of the other languages covered in the Bodley's manuscript collection, and indeed in the 40's he had actively encouraged our own Professor Edward Ullendorff, a close personal friend, to produce and publish his Catalogue of the Ethiopic manuscripts in the Bodleian Library, Vol. II (Oxford, 1951), a task which had lain in abeyance since the last listing compiled by Dillmann in 1848 .

In every respect Beeston's career at the Bodleian Library had been positive and productive. But he had not given up his philological interests and, apart from a handful of articles on Arabic subjects, often dealing with manuscripts in the Bodleian collection, it was during this period that he really began to make his mark in the South Arabian field, when some 22 articles on that subject appear under his name. Six of them belong to his ongoing series, 'Notes on Old South Arabian lexicography', where he successfully shed the irrelevancies of interpretation introduced by his more sanguine predecessors from their pillaging of the entire range of Semitic lexica to support their often preconceived interpretations, in favour of his own shrewd and critical evaluations based on internal context. The massive advances in interpretation and understanding achieved since the $60 \mathrm{~s}$, largely as a result of Beeston's own researches, may indeed have rendered some of his early findings out-of-date. Beeston would have been the first to acknowledge this. But most of his work from that early period has stood the test of time.

When the Laudian Professorship of Arabic fell vacant in 1955 with the departure of Sir Hamilton Gibb to Harvard, Beeston's scholarly credentials were well established--at least to that handful of scholars, mostly epigraphists, who were familiar with his work. One of these was Godfrey Driver, Professor of Comparative Semitic Philology at Magdalene College. Beeston, by nature a modest man, had no particular enthusiasm to apply for the Laudian Chair, no doubt to some extent because of the administrative duties which would follow, but more so since he regarded his exposure to advanced Arabic study too limited to impress the electors. After all, his undeniable contribution as a Semitic and Arabic philologist simply represented the fruits of his own personal interests and, much as it would be most gratifying to be paid for what one likes to do, he questioned the wisdom of taking on such an awesome responsibility. Driver's counsels, however, prevailed, not only on Beeston but also on the Electors, and he duly became Laudian Professor, with a Fellowship of St John's College, though not without some reservations on the part of certain figures in the academic world. He was soon to prove the latter wrong. He plunged into his duties in his new post with characteristic vigour, engaging in a programme of heavy teaching and introducing some of the innovations which his previous experience had suggested might be desirable, notably the introduction of Modern Arabic into the syllabus. His South Arabian publications continued unabated, with over 40 significant articles and several short monographs on vocabulary, chronology and religion appearing during his tenure of the Chair. His responsibilities within Arabic in their turn provoked a number of articles on textual matters, three manuals on the written language for the benefit of the non-specialist Arabist for whom knowledge of the minutiae of $i^{\prime} r a \bar{b} b$ would really have little benefit and containing useful advice on the 
handling of problems internal to the Arabic system, and an edited selection of the poems of Bashshār (1977). As often as not these contributions reflected Beeston's concern with the inner workings of the language rather than with the comprehensive understanding of a subject area, but his recognition of the importance of a proper appreciation of such features as a prerequisite to further study stands out clearly in his method. His experience of Arabic as a total language led to what is probably his masterpiece, The Arabic language today (London, 1970), a concise, perceptive, and informed study of the place of Arabic in the modern world and defining the theoretical bases of its grammar and syntax. Often difficult to read, it nevertheless is widely recognized as an index of his scholarly acumen. The effect of Beeston's method and scholarly caution on his students has been considerable and has often been commented upon in the numerous tributes which have been paid to his memory. In 1965 he was elected a Fellow of the British Academy.

After his retirement in 1979 , he seemed to acquire a new lease of life, mostly, of course, invested in his beloved South Arabia. The opportunity had come to promote one of his favourite schemes, a dictionary of the Sabaic language, making it accessible to the non-specialist without the need to consult a host of technical articles in obscure and out-of-the-way sources. By now the time was propitious for such an ambitious undertaking. In the early $60 \mathrm{~s}$ the substantial text materials yielded by the excavation of the temple of 'LMQH at Mārib by the American Foundation for the Study of Man in the 50s had been published. The available vocabulary of Sabaic had been substantially increased and the chances of determining with reasonable accuracy the contexts in which individual items occurred had risen appreciably. The task could only benefit from the friendly and positive collaboration of a group proven scholars, and the establishment of the Seminar for Arabian Studies in London in 1969 had provided the ideal venue for such to meet. The Seminar had proved an immense success and the participation of a number of prominent researchers in the field was virtually guaranteed year by year. When the Colloquium on Yemeni Civilization held in Aden in 1975 stressed the urgent need for such a scholarly tool for South Arabianists and Semitists alike, a select group was established, comprising Beeston, Jacques Ryckmans of Louvain, Walter Müller of Marburg, and Mahmūd Ghūl of Yarmūk. Meetings were held at regular intervals, one of which this writer was privileged to attend. Discussion and debate were vigorous, yet the atmosphere was cordial and constructive, so that it was usually possible to arrive at a consensus on problematic items. Perhaps the healthiest aspect of the deliberations was the readiness of all participants to consider suitability to context rather than the comparative data other languages in elucidating meaning.

The fruits of their lucubrations saw the light of day in 1982 in the Sabaic dictionary/Dictionnaire Sabéen, published in attractive format by Peeters of Louvain with a generous subvention from the University of Sanaa. Trilingual English-French-Arabic definitions were provided for the vocabulary of all Sabaic texts published up till about 1981. The book was well received and readily established itself as the definitive study, despite the judicious question mark attaching to the occasional definition. Many years earlier, in 1962, Beeston had published his $A$ descriptive grammar of Epigraphic South Arabian, based on the limited corpus of texts available at that time. It was a relatively slim work, but descriptions and definitions were concise and economical, though shrewd and very much to the point. Unfortunately, the availability of the Mahram Bilqīs texts shortly thereafter and of a number of other collections 
over the next twenty years detracted somewhat from the utility of Beeston's little grammar, and an updated version appeared in 1982 in his Sabaic grammar (Journal of Semitic Studies Monograph, no. 6). Again a slim volume of only 76 pages, it is packed with information on the language encompassed within concise and well thought out formulations. An edition in Arabic was translated by the author himself.

At the same time, throughout his years of retirement, articles continued to flow from his pen on almost every aspect of South Arabian civilization. Beeston was never a man to be over possessive of his opinions. He was happy to indulge in debate and always willing to revise his views in the light of subsequent consideration. His earlier work had laid a firm foundation for his understanding of almost every aspect of South Arabian society and in his last 15 years there appeared a number of studies which, as it were, summed up the implications of his position within his understanding of the total culture. Significant contributions were made by him on chronology, history (particularly of the early sixth century A.D.), tribalism, society, and religion, much of which helped to invigorate debate on the part of the ever-increasing band of specialists who were now taking up the field. A number of honours were bestowed on him at this time, notably the Lidzbarski Medal for Semitic Epigraphy by the Deutsche Morgenländische Gesellschaft in 1983. An Honorary Fellow of SOAS, he served from 1980 till 1985 on the Governing Body. It would perhaps be no exaggeration to say that Beeston was the most influential figure in the field during the second half of this century, indeed that he created South Arabian studies as we know them today and changed them from an under-appreciated and misunderstood preserve of the armchair specialist into a clearly defined and increasingly well understood domain within the ancient Near East.

In himself Beeston was a rather shy person, though for all that sociable and affable. An inveterate college man, he liked formality but remained his approachable, witty self, not much given to small talk, though he could hold his own there when necessary. He was particularly helpful to the young scholar who could identify with his interests in whichever aspect. In return he was highly revered by his colleagues and disciples. As a teacher he was patient and forbearing with his students as they struggled to comprehend a passage of Harīī or an intractable verse of Abbasid poetry, even indeed, on the rare occasion when such a situation arose, with the fledgeling epigraphist wrestling with a tortuous Qatabanian legal formulation. He was particularly so with his research students. Although supervisions in the distant past were less frequently required than modern bureaucracy might insist on now, this writer well remembers the discussion of the first chapter for his own thesis around 1959 in Beeston's dark and smoke-filled college room. Illogicalities, misunderstandings, and inadequate formulations were courteously, indeed affably highlighted and demolished, then discussed and the materials reassembled in a more convincing manner. One felt instinctively that there was a great deal to be learned from the man and the humiliation and disorientation of that first exposure remained an isolated incident in a long and happy association with his mentor. Nowhere was the high estimate of Beeston's scholarship more pronounced than at the annual assemblies of the Seminar for Arabian Studies, which he attended without fail from its inception. The Seminar soon became known as providing an opportunity to meet the great man, along with the other stalwarts, Serjeant, Müller, Ryckmans, and, till his untimely death, Ghūl. The contributions and discussions of these giants attracted a large audience and at the breaks their company would be avidly sought by all. It would be true to say that they were 
the Seminar for Arabian Studies. It might be the case that his commitment to his subject was so intense that he would be liable to talk shop only, but there was no lack of petitioners for that pleasant experience.

Freddie Beeston collapsed and died at the gate of St John's College on the morning of 29 September 1995 . It was a bitter blow to all who knew him, but the memory of his friendship and conviviality will live on and must surely provide some consolation for his loss. At least he will have had the satisfaction of knowing that the bases of an entire epigraphic discipline owe so much to his personal contribution to it.

A. K. IRVINE

School of Oriental and African Studies, London 